\title{
Effects of Additives on Microstructures of Titanate Based Nanotubes Prepared by the Hydrothermal Process
}

\author{
Takashi Kubo $^{1, *}$, Keijiro Sugimoto ${ }^{1}$, Takamasa Onoki ${ }^{1}$, Yuki Yamasaki ${ }^{2}$ and Atsushi Nakahira ${ }^{1,3}$ \\ ${ }^{1}$ Department of Materials Science, Graduate School of Engineering, Osaka Prefecture University, Sakai 599-8531, Japan \\ ${ }^{2}$ Department of Chemistry, Faculty of Economics, Hosei University, Tokyo 194-0298, Japan \\ ${ }^{3}$ IMR, Osaka Center, Tohoku University, Sakai 599-8531, Japan
}

Silica-containing $\mathrm{TiO}_{2}$-derived titanate nanotubes were prepared by the addition of a small amount of tetraethyl orthosilicate (TEOS) to $\mathrm{TiO}_{2}$-derived titanate nanotubes prepared by the hydrothermal process and a subsequent heat-treatment at $473 \mathrm{~K}$ in air. The microstructure and thermal behavior of synthesized silica containing $\mathrm{TiO}_{2}$-derived titanate nanotubes were investigated by various methods such as $\mathrm{X}$-ray diffraction (XRD), X-ray absorption fine structure (XAF), and X-ray photoelectron spectroscopy (XPS). As a result, the addition of a small amount of TEOS leaded to the improvement of the thermal stability for $\mathrm{TiO}_{2}$-derived titanate nanotubes. XPS results revealed that $\mathrm{Si}$ was combined onto the surface of $\mathrm{TiO}_{2}$-derived titanate nanotubes, forming partial $\mathrm{Si}$-O-Ti chemical bonds. Therefore, it was inferred that the thermal stability could be modified by forming partial $\mathrm{Si}$-O-Ti chemical bonds at interface of silica and $\mathrm{TiO}_{2}$-derived titanate nanotubes. [doi:10.2320/matertrans.MC200807]

(Received November 5, 2008; Accepted January 19, 2009; Published March 4, 2009)

Keywords: titanate nanotube, silica, X-ray absorption fine structure, X-ray photoelectron spectroscopy, chemical binding

\section{Introduction}

Oxide nanotubes, nanowire, and nanofiber constitute a promising new class of materials having uniform dimensions and well-developed morphologies. In particular, since the discovery of carbon nanotubes, ${ }^{1)}$ the syntheses of micro- and nanotubes of $\mathrm{TiO}_{2}$ have been attempted by various methods such as template methods ${ }^{2-4)}$ Kasuga et al. treated $\mathrm{TiO}_{2}$ at $383 \mathrm{~K}$ in $10 \mathrm{M} \mathrm{NaOH}$ aqueous solutions without the replication or template and nanotubes with $8 \mathrm{~nm}$ in diameter and $100 \mathrm{~nm}$ in length were obtained by their experiments. ${ }^{5)}$ These $\mathrm{TiO}_{2}$-derived nanotubes are notable nanoscale-materials because of their nanotubular structures and high surface areas. Therefore, several application studies on such as electrochromism, ${ }^{6)}$ bone regeneration, ${ }^{7)}$ proton conduction, ${ }^{8)}$ photoinduced hydrophilicity, ${ }^{9)}$ photocatalysts, ${ }^{10-12)}$ and dyesensitizing solar batteries ${ }^{13)}$ have been conducted by many researchers, although discussion about the structure and formation mechanism are in problems. ${ }^{14-20)}$ Furthermore, preparations of thin film and bulk for these nanotubes have been attempted extensively. ${ }^{21-23)}$ On the contrary, these $\mathrm{TiO}_{2}$-derived nanotubes can not keep nanotubular structures at high heat $(573 \mathrm{~K} \sim){ }^{24,25)}$ For that reason, it is considered that these $\mathrm{TiO}_{2}$-derived nanotubular materials are restricted in their practical application because of their poor thermostability. So, the synthesis of silica-supported $\mathrm{TiO}_{2}$-derived nanotubes was attempted to improve their thermal stability for nanotubular structures in this study. Moreover, the composite with silica is also expected to provide functions such as an adsorptive capacity, leading to the modification of the photocatalytic activity. In fact, as for $\mathrm{TiO}_{2}$ nanoparticles, the effectiveness of the addition of silica for enhancement of the phase stability ${ }^{26-29)}$ and the photocatalytic activity ${ }^{30,31)}$ has been reported in large numbers.

In the present work, silca-containing $\mathrm{TiO}_{2}$-derived nanotubes were prepared by hydrothermal treatments of anatase-

*Graduate Student, Osaka Prefecture University type $\mathrm{TiO}_{2}$ in $\mathrm{NaOH}$ aqueous solutions and a subsequent addition of tetraethyl orthosilicate (TEOS) to these nanotubes in water/ethanol system. The microstructure and thermal behavior of synthesized silica-containing $\mathrm{TiO}_{2}$-derived nanotubes were investigated in detail. In special, the effect of the additive TEOS on the local structure around $\mathrm{Ti}$ atom was investigated by Ti K-edge XAFS. Furthermore, the surface states of silica-containing $\mathrm{TiO}_{2}$-derived nanotubes were also investigated by XPS.

\section{Experimental Procedure}

The synthesis of $\mathrm{TiO}_{2}$-derived nanotubes was attempted via the hydrothermal process. Commercial anatase-type $\mathrm{TiO}_{2}$ powder $\left(3 \mathrm{~m}^{2} / \mathrm{g}\right.$, Kojundo Chem., Japan) was used as a starting material. $2 \mathrm{~g}$ of anatase powder was added in $10 \mathrm{M}$ $\mathrm{NaOH}$ aqueous solutions $(20 \mathrm{ml})$. Then the specimen was treated under a hydrothermal reaction at $383 \mathrm{~K}$ for $96 \mathrm{~h}$. The obtained product after the hydrothermal treatment were sufficiently washed with de-ionized water and dilute $\mathrm{HCl}$ aqueous solution $(0.1 \mathrm{M})$ and was subsequently separated from the washing solution by filtration. This treatment was repeated until the washing water showed $\mathrm{pH}<7$. The final $\mathrm{pH}$ value of the washing water was 6.8. This was dried at $323 \mathrm{~K}$ for more than $12 \mathrm{~h}$ in an oven. The obtained nanotubular product $(1 \mathrm{~g})$ was mixed with TEOS $(0.1,0.3$, and $0.5 \mathrm{ml})$ in water/ethanol system and then heat-treated at $473 \mathrm{~K}$ for $6 \mathrm{~h}$ in air. The obtained silica-containing samples were heated at 573 and $673 \mathrm{~K}$ for $2 \mathrm{~h}$ in air. For comparison with silica containing products, the sample without the addition of TEOS was also heated at 573 and $673 \mathrm{~K}$ for $2 \mathrm{~h}$ in air.

The phase identification was carried out by XRD (Rint 2100, Rigaku Co., Ltd, Japan) method using $\mathrm{CuK} \alpha$ radiation at $40 \mathrm{kV}$ and $20 \mathrm{~mA}$. The XRD profiles were collected between 5 to $60^{\circ}$ of $2 \theta$ angles with a step interval of $0.02^{\circ}$ and scanning rate of $1^{\circ} / \mathrm{min}$. Various microstructural analyses were performed by scanning electron microscope (SEM, 
S-4500, Hitachi, Japan) with accelerating voltage of $15 \mathrm{kV}$ and transmission electron microscope (TEM, JEM2010/SP, JEOL, Japan) with accelerating voltage of $200 \mathrm{kV}$. The concentration of sodium in prepared samples was analyzed by energy dispersive X-ray (EDX) analysis. The Si/Ti molar ratio was measured by X-ray fluorescence spectrometry (XRF, XRF-1700, SHIMADZU, Japan) using $\mathrm{CuK} \alpha$ radiation at $40 \mathrm{kV}$ and $95 \mathrm{~mA}$. Nitrogen adsorption isotherms at $77 \mathrm{~K}$ were obtained by automatic gas adsorption measurement apparatus (BELSORP 18PLUS-SPL, Japan-BEL, Japan). Some products were pretreated at $403 \mathrm{~K}$ for $10 \mathrm{~h}$.

Ti K-edge XAFS was recorded at room temperature at BL01B1 beamline of SPring 8 in Japan. Ti K-edge XAFS data for this study was corrected with transmission mode using the $\mathrm{Si}$ (111) double crystal monochromater $(2 \mathrm{~d}=$ $0.627 \mathrm{~nm})$. The data were collected with the ionization chambers filled with gas ( $\mathrm{I}_{0}$ chamber: $\mathrm{He} / \mathrm{N}_{2}=7 / 3$, I chamber: $\mathrm{N}_{2}$ ). For the XAFS measurements, the samples were prepared as pellets with the thickness varied to obtain a 0.5-1 jump at the Ti $\mathrm{K}$ absorption edge. Ti metallic foil was used to carry out for the energy calibration. X-ray absorption near-edge structure (XANES) was analyzed by subtracting a linear background computed by least-square fitting from the pre-edge region and normalized. Extended X-ray absorption fine structure (EXAFS) was analyzed by using standard methods. The pre-edge region was subtracted, and then the EXAFS spectrum was extracted by fitting the absorption coefficient with a cubic spline method. Fourier transformation of the $k^{3}$-weighted EXAFS oscillation from $k$ ( $k$ is the photoelectron wavenumber) space to $r$ space was performed over the range $0.25-1.05 \mathrm{~nm}^{-1}$ to obtain radial distribution function (FT-EXAFS). The analysis of EXAFS data conducted using the commercial software "REX2000" (Rigaku Co. Ltd., Japan).

The XPS analysis was performed in an ultrahigh vacuum (less than $1.33 \times 10^{-6} \mathrm{~Pa}$ ) using an ULVAC-PHI 5500MT system, with $\mathrm{Mg} \mathrm{K} \alpha(h v=1253.6 \mathrm{eV}) \mathrm{X}$-ray source operated at $15 \mathrm{kV}$. Binding energies were referenced to $\mathrm{C} 1 \mathrm{~s}$ level of residual graphitic carbon.

\section{Results and Discussion}

Figure 1(A) shows a typical TEM image of the product prepared by the hydrothermal treatment of anatase-type $\mathrm{TiO}_{2}$ at $383 \mathrm{~K}$ at $96 \mathrm{~h}$ in $10 \mathrm{M} \mathrm{NaOH}$ aqueous solutions. As shown in Fig. 1(A), the obtained product possessed nanotubular structures with about $10 \mathrm{~nm}$ in outer diameter and $5 \mathrm{~nm}$ in inner diameter and a few hundred $\mathrm{nm}$ in length, and they were open-end with several wall layers on both sides. The measured interlayer spacing was about $0.90 \mathrm{~nm}$. Figure 1(B) shows XRD patterns of the obtained nanotubular product before and after heat treatments at 573 and $673 \mathrm{~K}$ in air. In the XRD pattern of the nanotubular product before the heat-treatment, the broad reflection peaks were observed at $2 \theta$ of approximately $9^{\circ}, 24^{\circ}, 30^{\circ}, 48^{\circ}$ and $62^{\circ}$. The XRD pattern of the synthesized nanotubular product in this study was consistent with $\mathrm{TiO}_{2}$-derived nanotubes prepared in other previous literatures..$^{6-9,11,12,19,20)}$ In particular, the peak at $2 \theta=c a .9^{\circ}(\mathrm{d}=0.95 \mathrm{~nm})$ was corresponding to the interlayer spacing value measured by TEM observation,
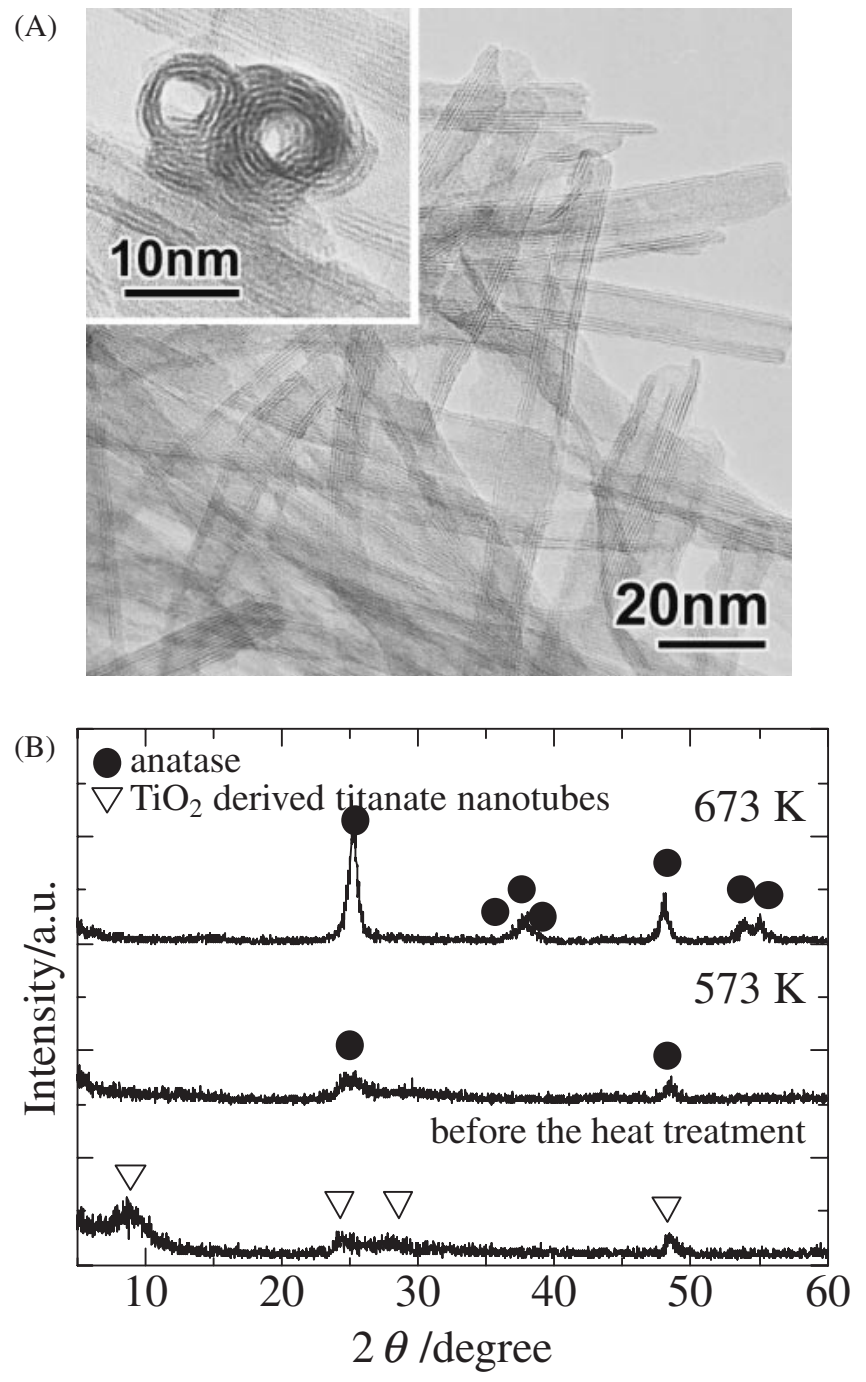

Fig. 1 (A) Typical TEM images of the product prepared by the hydrothermal treatment of anatase at $383 \mathrm{~K}$ for $96 \mathrm{~h}$ and the subsequent washing treatment with $\mathrm{H}_{2} \mathrm{O} / \mathrm{HCl}$. (B) XRD patterns of the nanotubular products before and after heat treatments at 573 and $673 \mathrm{~K}$ for $2 \mathrm{~h}$ in air.

indicating that this product might be composed of layered titanate structure. Sodium hardly could be detected in the nanotubular product according to surface analytic methods such as EDX and XPS. Therefore, it was indicated that sodium could be removed from the product by the $\mathrm{H}_{2} \mathrm{O}$ / $\mathrm{HCl}$ washing treatment and that the product might be mainly composed of the H-type of titanate. The BrunauerEmmett-Teller (BET) surface area value obtained by $\mathrm{N}_{2}$ adsorption measurement for $\mathrm{TiO}_{2}$-derived titanate nanotube was ca. $250 \mathrm{~m}^{2} / \mathrm{g}$.

As shown in Fig. 1(B), in XRD pattern of the sample after a heat-treatment at $573 \mathrm{~K}$, diffraction peaks derived from anatase-type $\mathrm{TiO}_{2}$ were slightly observed. Particularly, in the case of a heat-treatment at $673 \mathrm{~K}, \mathrm{TiO}_{2}$-derived titanate nanotubes mostly transferred to anatase-type $\mathrm{TiO}_{2}$. Moreover, SEM result shows that this sample prepared by a heattreatment at $673 \mathrm{~K}$ possessed non-tubular structures, and this sample was mainly composed of spherical particles (Fig. 2).

Silica-containing $\mathrm{TiO}_{2}$-deirved titanate nanotubes were attempted to synthesize by the addition of TEOS $(0.1,0.3$, and $0.5 \mathrm{ml}$ ) to $\mathrm{TiO}_{2}$-derived titanate nanotubes in water/ 


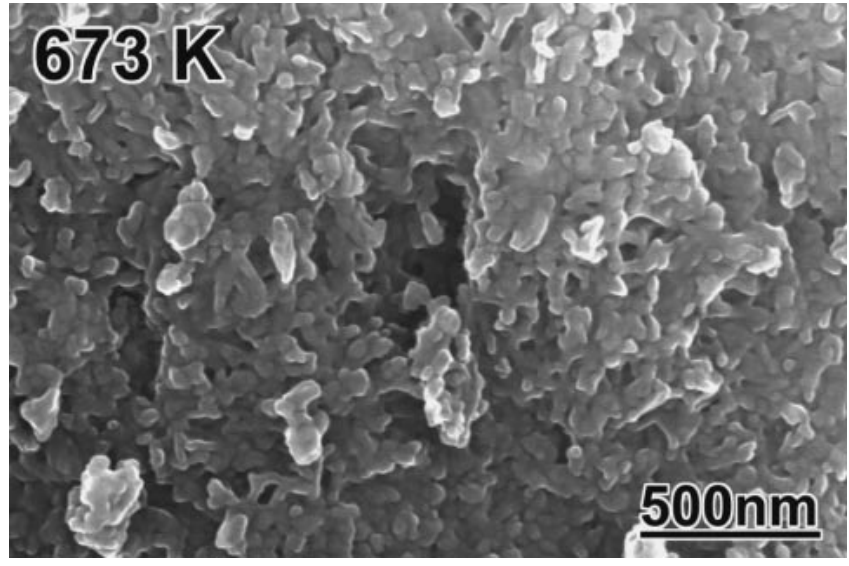

Fig. 2 Typical SEM image of $\mathrm{TiO}_{2}$-derived titanate nanotubes heat-treated at $673 \mathrm{~K}$ for $2 \mathrm{~h}$ in air.

ethanol and a subsequent heat-treatment at $473 \mathrm{~K}$ in air. According to XRF measurements, $\mathrm{Si} / \mathrm{Ti}$ molar ratios of samples prepared by additions of $0.1,0.3$, and $0.5 \mathrm{ml}$ of TEOS were $0.013,0.026$, and 0.033 , respectively. Figure 3 shows XRD patterns of these silica-containing samples before and after heat-treatments. XRD patterns of silicacontaining samples before heat-treatments were similar with that of $\mathrm{TiO}_{2}$-derived titanate nanotubes. In XRD patterns of samples after heat-treatments, the peaks intensity derived from anatase-type $\mathrm{TiO}_{2}$ decreased with an increase in the amount of additive TEOS. Though typical SEM images of silica-containing samples (TEOS additive amount: $0.5 \mathrm{ml}$ ) before and after heat-treatments are shown in Fig. 4, silicacontaining sample heat-treated at $673 \mathrm{~K}$ had nanowhiskerlike morphologies and possessed high BET value $\left(174 \mathrm{~m}^{2} / \mathrm{g}\right)$, indicating that this sample mostly maintained nanotubular structures after a heat-treatment at $673 \mathrm{~K}$. Thus, the small additive TEOS had any effect on thermal behavior of $\mathrm{TiO}_{2}-$ derived titanate nanotubes, leading to the modification of their thermal stability for nanotubular structures. The effect of the additive TEOS on the local structure around $\mathrm{Ti}$ atom was investigated by Ti K-edge XAFS.

Figure 5 shows Ti K-edge XANES spectra for $\mathrm{TiO}_{2}$ derived titanate nanotubes and silica-containing $\mathrm{TiO}_{2}$-derived titanate nanotubes (TEOS additive amount: $0.5 \mathrm{ml}$ ). The edge region in the absorption spectra provides much information on the environment geometry and electronic structure of the absorption atom. In Ti K-edge XANES, the characteristic pre-edge peaks were also observed at 4960 $4970 \mathrm{eV}$. These pre-edge features are widely used to derive information on the coordination environment of $\mathrm{Ti}$ atom. ${ }^{20,32-35)}$ As shown in Fig. 5, the edge energy position of silica-containing $\mathrm{TiO}_{2}$-derived titanate nanotubes was very close to that of $\mathrm{TiO}_{2}$-derived titanate nanotubes, and their pre-edge features illustrated similar features each other. Therefore, the symmetry of the $\mathrm{Ti}$ environment in $\mathrm{TiO}_{2}$ derived titanate nanotubes has hardly changed with the addition of a small amount of TEOS.

Figures 6(A) shows $k^{3}$-weighted EXAFS oscillations for $\mathrm{TiO}_{2}$-derived titanate nanotubes and silica-containing $\mathrm{TiO}_{2}-$ derived titanate nanotubes (TEOS additive amount: $0.5 \mathrm{ml}$ ). For EXAFS oscillations, as shown in Fig. 6(A), a marked
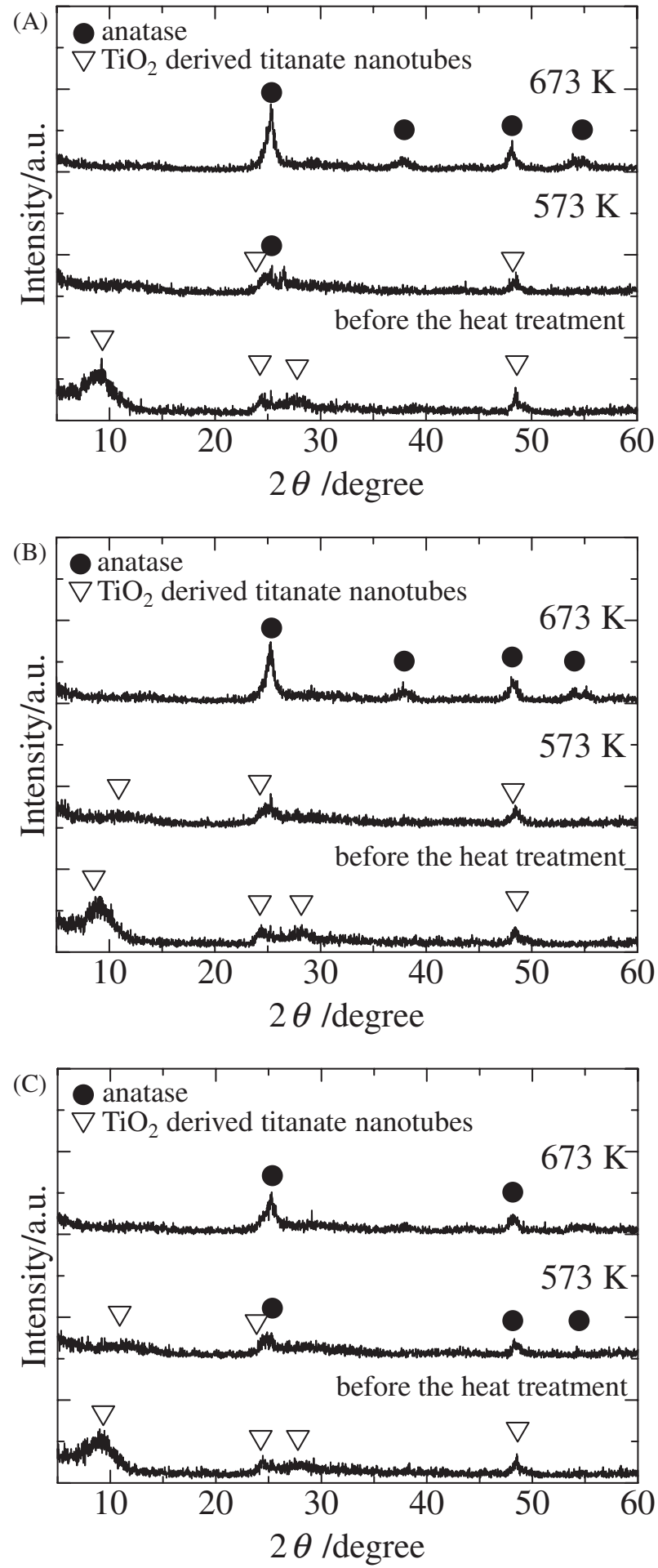

Fig. 3 XRD patterns of $\mathrm{TiO}_{2}$-derived titanate nanotubes with addition of TEOS before and after heat-treatments at 573 and $673 \mathrm{~K}$ for $2 \mathrm{~h}$ in air. Amount of addition of TEOS to titanate nanotube (1 g): (A) $0.1 \mathrm{ml}$, (B) $0.3 \mathrm{ml}$, and (C) $0.5 \mathrm{ml}$.

difference between these samples could not be confirmed. Figure 6(B) also shows FT-EXAFS for these samples. They represent radial distribution function plots around the $\mathrm{Ti}$ atom, and the first peak was indicated as the coordination number corresponding to the Ti-O bond distance. The magnitudes of the second peak and subsequent ones were further small in FT-EXAFS for $\mathrm{TiO}_{2}$-derived titanate nanotubes. This indicated that $\mathrm{TiO}_{2}$-derived titanate nanotubes 

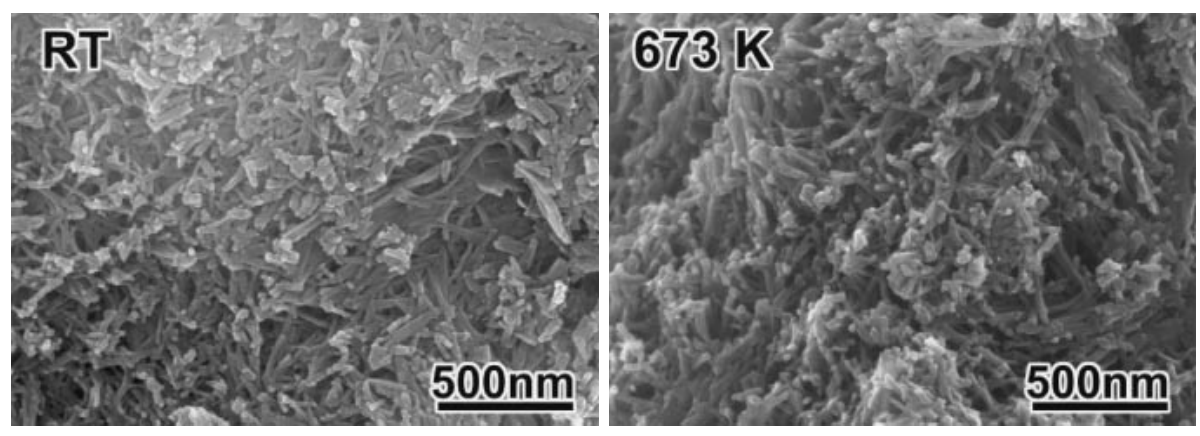

Fig. 4 Typical SEM images of silica-containing $\mathrm{TiO}_{2}$-derived titanate nanotubes before and after a heat treatment at $673 \mathrm{~K}$ for $2 \mathrm{~h}$ in air.

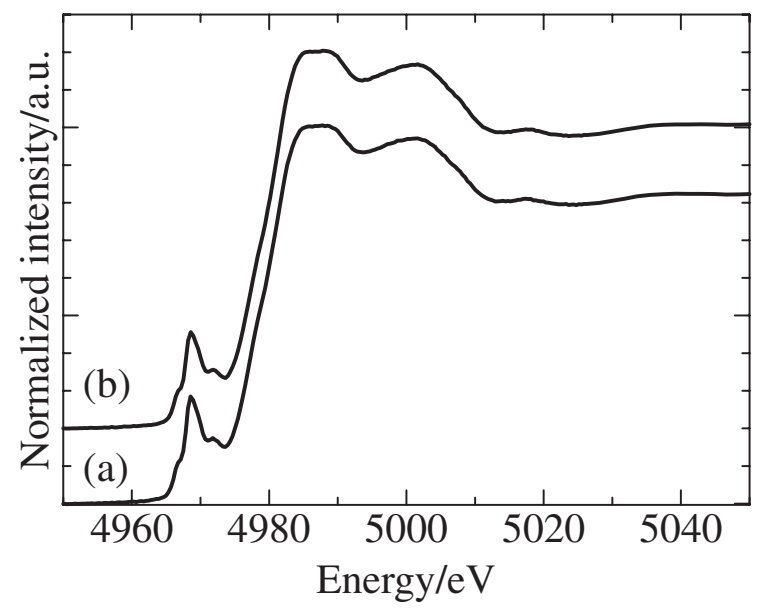

Fig. 5 Ti K-edge XANE spectra for (a) $\mathrm{TiO}_{2}$-derived titanate nanotubes and (b) silica containing $\mathrm{TiO}_{2}$-derived titanate nanotubes (TEOS additive amount: $0.5 \mathrm{ml})$.

had only periodic structures in short order. Furthermore, in order to the structural parameters, the curve fitting of the Ti$\mathrm{O}$ shell within the range of $0.06-0.2 \mathrm{~nm}$ was performed by inverse FT. The later each value was obtained from the simulation of the experimental spectrum using the theoretical curves calculated by Mckale et al. ${ }^{36)}$ For $\mathrm{TiO}_{2}$-derived titanate nanotubes, the nearest $\mathrm{Ti}-\mathrm{O}$ distance and its average coordination number obtained by the curve fitting were $0.192 \mathrm{~nm}$ and 5.2, respectively. In our previous study, the local structure of $\mathrm{TiO}_{2}$-derived titanate nanotubes prepared by the hydrothermal process has been investigated by XAFS, and the result detail has been reported. ${ }^{20)}$ As shown in Fig. 6(B), the radial distribution function plot around the Ti atom for silica-containing $\mathrm{TiO}_{2}$-derived titanate nanotubes was very similar to that of $\mathrm{TiO}_{2}$-derived titanate nanotubes. In particular, the nearest Ti-O peak geometries of these samples were almost the same, and the nearest Ti-O distance and its average coordination number were $0.192 \mathrm{~nm}$ and 5.25, respectively. This result indicated that $\mathrm{TiO}_{x}$ polyhedra in $\mathrm{TiO}_{2}$-derived titanate nanotubes has hardly changed due to the addition of a small amount of TEOS, and this EXAFS result also agrees with XANES result. Thus, Ti K-edge XAFS results revealed that the addition of a small amount of TEOS did not have much effect on local structures around Ti atom.

The surface states of silica-containing $\mathrm{TiO}_{2}$-derived titanate nanotubes were also investigated by XPS analysis

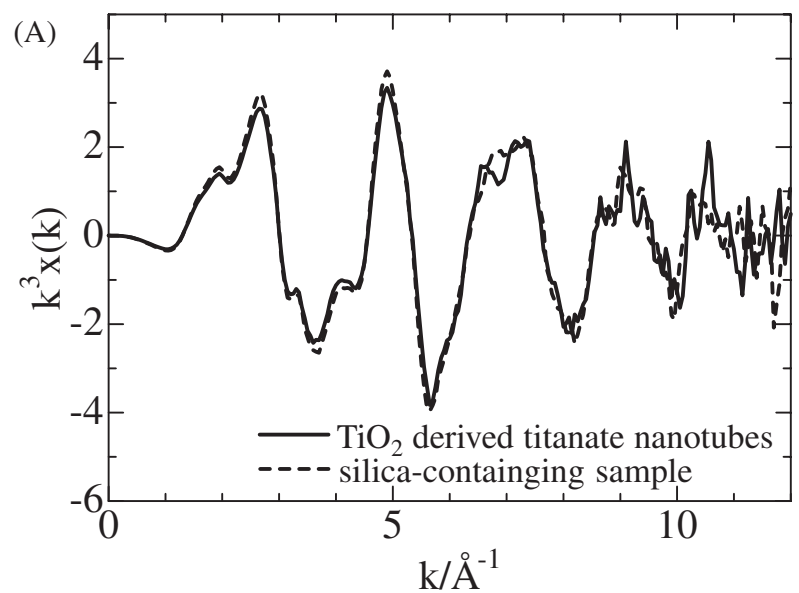

(B)

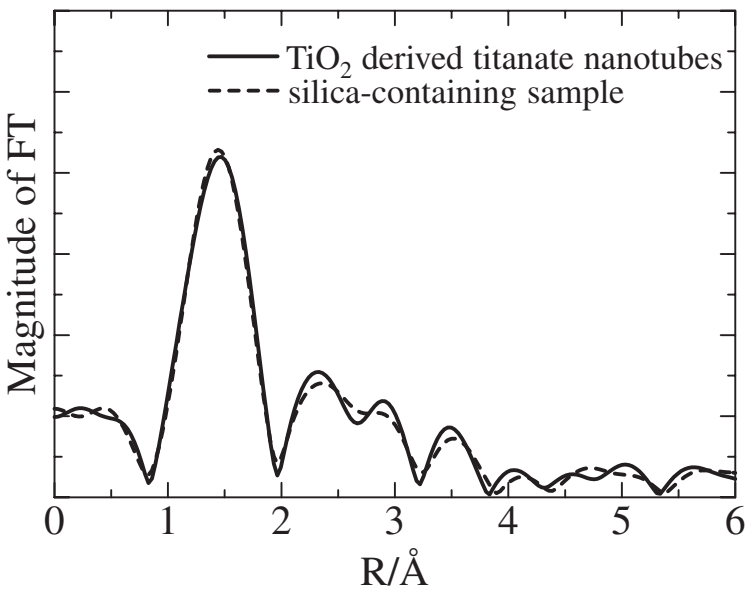

Fig. 6 (A) $\mathrm{k}^{3}$-weighted EXAFS oscillations and (B) FT-EXAFS for $\mathrm{TiO}_{2}$ derived titanate nanotubes and silica containing $\mathrm{TiO}_{2}$-derived titanate nanotubes (TEOS additive amount: $0.5 \mathrm{ml}$ ).

in this study. Figure 7 shows Si 2p XPS of silica-containing $\mathrm{TiO}_{2}$-derived titanate nanotubes (TEOS additive amount: $0.5 \mathrm{ml}$ ). The peak derived from $\mathrm{Si}^{4+}$ in silica was located at around $103 \mathrm{eV}^{37)}$ In fact, the binding energy of $\mathrm{Si} 2 \mathrm{p}$ peak for commercial silica quartz was also located at $103.2 \mathrm{eV}$ in this measurement. For silica-containing $\mathrm{TiO}_{2}-$ derived titanate nanotubes, the binding energy of Si $2 \mathrm{p}$ peak was located at $102.5 \mathrm{eV}, 0.7 \mathrm{eV}$ lower than $\mathrm{Si} 2 \mathrm{p}$ peak for commercial silica. Therefore, it was considered that the state of $\mathrm{Si}$ species in silica-containing $\mathrm{TiO}_{2}$-derived titanate nanotubes could be different from that of $\mathrm{Si}$ species in commercial silica. 


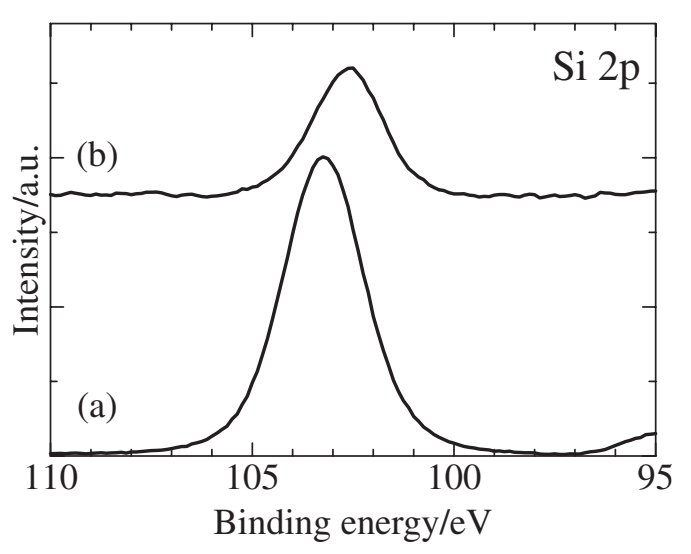

Fig. 7 Si 2p XPS for (a) commercial silica and (b) silica containing $\mathrm{TiO}_{2}$ derived titanate nanotubes (TEOS additive amount: $0.5 \mathrm{ml}$ ).
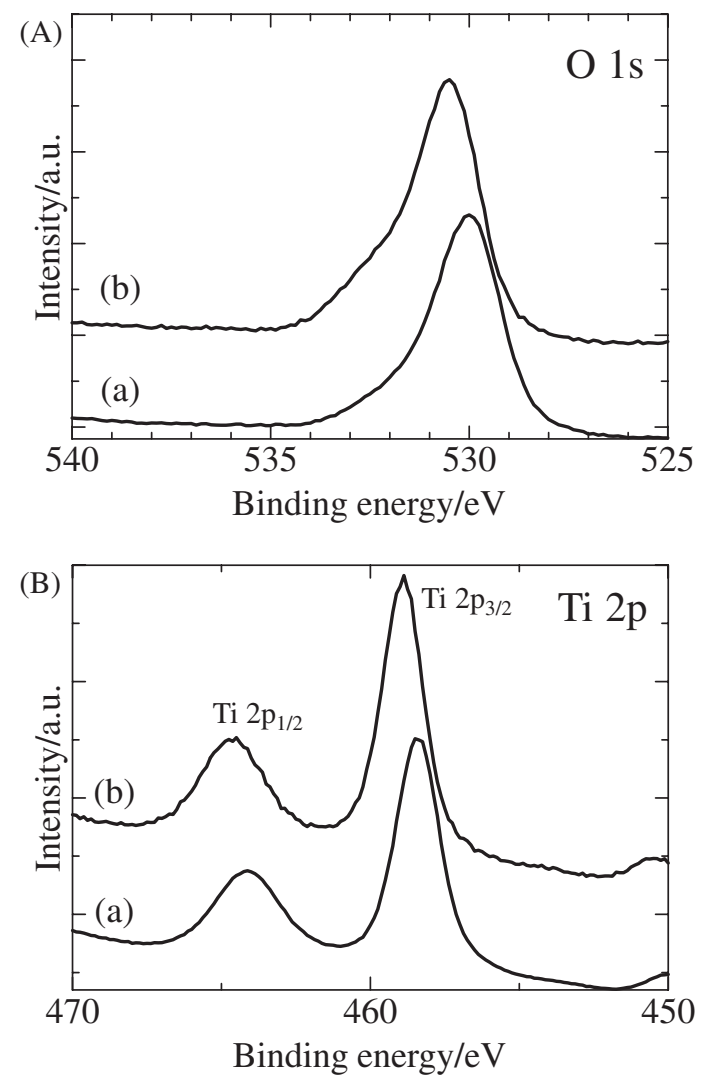

Fig. 8 (A) $\mathrm{O} 1 \mathrm{~s}$ and (B) $\mathrm{Ti} 2 \mathrm{p}$ XPS for $\mathrm{TiO}_{2}$-derived titanate nanotubes and silica containing $\mathrm{TiO}_{2}$-derived titanate nanotubes (TEOS additive amount: $0.5 \mathrm{ml})$.

$\mathrm{O}$ 1s and Ti 2p XPS of $\mathrm{TiO}_{2}$-derived titanate nanotubes and silica-containing $\mathrm{TiO}_{2}$-derived titanate nanotubes are also shown in Fig. 8. As shown in Fig. 8(A), the binding energy of $\mathrm{O} 1 \mathrm{~s}$ peak for $\mathrm{TiO}_{2}$-derived titanate nanotubes was mainly located at $530 \mathrm{eV}$. On the other hand, the binding energy of $\mathrm{O} 1 \mathrm{~s}$ peak for silica-containing $\mathrm{TiO}_{2}$-derived titanate nanotubes was mainly located at $530.5 \mathrm{eV}$. Thus, the binding energy of $\mathrm{Si} 2 \mathrm{p}$ peak slightly shifted to higher binding energy by the addition of a small amount of TEOS. In Ti $2 p$ XPS, the binding energy of $\mathrm{Ti} 2 \mathrm{p}_{3 / 2}$ peak for $\mathrm{TiO}_{2}$ derived titanate nanotubes was $458.3 \mathrm{eV}$ (Fig. 8(B)). Ti $2 \mathrm{p}_{3 / 2}$ peak for silica-containing $\mathrm{TiO}_{2}$-derived titanate nanotubes was $458.9 \mathrm{eV}, 0.6 \mathrm{eV}$ higher than that for $\mathrm{TiO}_{2}$-derived titanate nanotubes. From these XPS results, for silicacontaining $\mathrm{TiO}_{2}$-derived titanate nanotubes, it is speculated that $\mathrm{Si}$ is combined onto the surface of $\mathrm{TiO}_{2}$-derived titanate nanotubes, forming partial Si-O-Ti chemical bonds. Because the electronegativity of $\mathrm{Si}$ is greater than that of $\mathrm{Ti}, \mathrm{O} 1 \mathrm{~s}$ peak for $\mathrm{TiO}_{2}$-derived titanate nanotubes is thought to have a chemical shift of $+0.5 \mathrm{eV}$. Moreover, a chemical shift in Ti $2 p_{3 / 2}$ XPS can be also derived from forming these $\mathrm{Si}-\mathrm{O}-\mathrm{Ti}$ chemical bonds. The decrease of the electron density around $\mathrm{Ti}$ atom results from the greater electronegativity of $\mathrm{Si}$ via $\mathrm{O}$ acting on Ti. The shielding effect is weakened, and then the binding energy is increased. ${ }^{38)}$

Consequently, the addition of a small amount of TEOS leaded to the improvement of the thermal stability for $\mathrm{TiO}_{2}$ derived titanate nanotubes prepared by the hydrothermal process. According to XPS, it was speculated that the thermal stability was modified by forming partial Si-O-Ti chemical bindings at interface of silica and $\mathrm{TiO}_{2}$-derived titanate nanotubes. Si-O-Ti bonds were investigated in studies on $\mathrm{TiO}_{2}-\mathrm{SiO}_{2}$ composites prepared by the sol-gel process. ${ }^{39-42)}$ According to these researches, thermodynamically there was no possibility of $\mathrm{Si}-\mathrm{O}$-Ti bonds breakage at low temperatures. For instance, Izutsu et al. has confirmed the presence of Si-O$\mathrm{Ti}$ bonds at $1073 \mathrm{~K}$. Therefore, it is expected that Si-O-Ti bonds at interface of silica and $\mathrm{TiO}_{2}$-derived titanate nanotubes could not also break up on heating. Thus if Si-O-Ti bonds could be stable at high heat, Si atoms might be inserted to titanate matrix during the heat-treatment, and there is a possibility that this insertion of $\mathrm{Si}$ atoms could retard the titanate-to-anatase phase transformation. The detailed analyses for the state of $\mathrm{Si}, \mathrm{Ti}$, and $\mathrm{O}$ in silica-containing $\mathrm{TiO}_{2}-$ derived titanate nanotubes and their stabilization mechanism are further investigation by using high resolution TEM (HRTEM) coupled with electron energy loss spectroscopy (EELS).

\section{Conclusions}

In this study, $\mathrm{TiO}_{2}$-derived titanate nanotubes with about $10 \mathrm{~nm}$ in outer diameter and $5 \mathrm{~nm}$ in inner diameter and a few hundred $\mathrm{nm}$ in length were attempted by the hydrothermal treatment at $383 \mathrm{~K}$ for $96 \mathrm{~h}$ of anatase-type $\mathrm{TiO}_{2}$ in $10 \mathrm{M}$ $\mathrm{NaOH}$ aqueous solutions and subsequent washing treatments with $\mathrm{H}_{2} \mathrm{O} / \mathrm{HCl}$. The obtained $\mathrm{TiO}_{2}$-derived titanate nanotubes $(1 \mathrm{~g})$ was mixed with TEOS $(0.1,0.3$, and $0.5 \mathrm{ml})$ in water/ethanol system and then heat-treated at $473 \mathrm{~K}$ for $6 \mathrm{~h}$ in air. The microstructure and thermal behavior of synthesized silica containing $\mathrm{TiO}_{2}$-derived titanate nanotubes were investigated by various methods such as XRD, XAFS, and XPS. As a result, the addition of a small amount of TEOS leaded to the modification of the thermal stability for $\mathrm{TiO}_{2}$ derived titanate nanotubes. From Ti K-edge XAFS analysis, the addition of a small amount of TEOS could not have much effect on local structures around $\mathrm{Ti}$ atom for $\mathrm{TiO}_{2}$-derived titanate nanotubes themselves. In contrast, according to XPS, the surface states of silica-containing $\mathrm{TiO}_{2}$-derived titanate nanotubes were different from those of $\mathrm{TiO}_{2}$-derived titanate nanotubes, and it was considered that $\mathrm{Si}$ could be combined onto the surface of $\mathrm{TiO}_{2}$-derived titanate nanotubes, forming 
partial $\mathrm{Si}-\mathrm{O}-\mathrm{Ti}$ chemical bonds. It was indicated that the thermal stability was modified by forming partial Si-O-Ti chemical bonds at interface of silica and $\mathrm{TiO}_{2}$-derived titanate nanotubes.

\section{Acknowledgment}

This work was partly supported by Grant-in-Aid for Scientific Research from Japan Society for the Promotion of Science (No. 20047011) and "Nano-materials Science for Atomic Scale Modification" from the Ministry of Education, Culture, Sports, Science and Technology, Japan. Ti K-edge XAFS measurements were carried out at BL01B1 of SPring8 (2006A1286, 2007B1666, 2008A1376). Authors greatly thanks for the technical support and discussion from JASRI.

\section{REFERENCES}

1) S. Iijima: Nature 354 (1991) 56-58.

2) P. M. Ajayan, O. Stephan, P. Redlich and C. Colliex: Nature 375 (1995) 564-567.

3) P. Hoyer: Langmuir 12 (1996) 1411-1413.

4) H. Imai, Y. Takei, K. Shimizu, M. Matsuda and H. Hirashima: J. Mater. Chem. 9 (1999) 2971-2972.

5) T. Kasuga, M. Hiramatsu, A. Hoson, T. Sekino and K. Niihara: Langmuir 14 (1998) 3160-3163.

6) H. Tokudome and M. Miyauchi: Angew. Chem. Int. Ed. 44 (2005) 1974-1977.

7) S. Kubota, K. Johkura, K. Asanuma, Y. Okouchi, N. Ogiwara, K. Sasaki and T. Kasuga: J. Mater. Sci: Mater. Med. 15 (2004) 1031-1035.

8) A. Thorne, A. Kruth, D. Tunstall, J. T. S. Irvine and W. Zhou: J. Phys. Chem. B 109 (2005) 5439-5444.

9) H. Tokudome and M. Miyauchi: Chem. Comm. 8 (2004) 958-959.

10) T. Akita, M. Okumura, K. Tanaka, K. Ohkuma, M. Kohyama, T. Koyanagi, M. Date, S. Tsubota and M. Haruta: Surf. Interface Anal. 37 (2005) 265-269.

11) A. Nakahira, T. Kubo, Y. Yamasaki, T. Suzuki and Y. Ikuhara: Jpn. J. Appl. Phys. 44 (2005) 690-692.

12) T. Kubo, H. Nagata, M. Takeuchi, M. Matsuoka, M. Anpo and A. Nakahira: Res. Chem. Intermed. 34 (2008) 339-346.

13) G. H. Du, Q. Chen, R. C. Che, Z. Y. Yuan and L. M. Peng: Appl. Phys. Lett. 79 (2001) 3702-3704.

14) Q. Chen, G. H. Du, S. Zhang and L. M. Peng: Acta Crystallogr. B 58 (2002) 587-593.

15) R. Ma, Y. Bando and T. Sasaki: Chem. Phys. Lett. 380 (2003) 577-582.

16) B. D. Yao, Y. E. Chan, X. Y. Zhang, W. F. Zhang, Z. Y. Yang and N. Wang: Appl. Phys. Lett. 82 (2003) 281-283.
17) J. Yang, Z. Jin, X. Wang, W. Li, J. Zhang, S. Zhang, X. Guo and Z. Zhang: Dalton Trans. (2003) 3898-3901.

18) W. Wang, O. K. Varghese, M. Paulose, C. A. Grimes, Q. Wang and E. C. Dickey: J. Mater. Res. 19 (2004) 417-422.

19) A. Nakahira, W. Kato, M. Tamai, T. Isshiki, K. Nishio and H. Aritani: J. Mater. Sci. 39 (2004) 4239-4245.

20) T. Kubo and A. Nakahira: J. Phys. Chem. C 112 (2008) 1658-1662.

21) Z. R. Tian, J. A. Voigt, J. Lin, B. Mckenzie and H. Xu: J. Am. Chem. Soc. 125 (2003) 12384-12385.

22) M. Miyauchi and H. Tokudome: Thin Solid Films 515 (2006) 20912096.

23) T. Kubo, Y. Yamasaki and A. Nakahira: J. Mater. Res. 22 (2007) 12861291.

24) R. Yoshida, Y. Suzuki and Y. Susumu: Mater. Chem. Phys. 91 (2005) 409-416.

25) B. Poudel, W. Z. Wang, C. Dames, J. Y. Huang, S. Kunwar, D. Z. Wang, D. Banerjee, G. Chen and Z. F. Ren: Nanotech. 16 (2005) 19351940.

26) M. Yoshikawa, K. Hirota and O. Yamaguchi: J. Am. Ceram. Soc. 80 (1997) 2749-2753.

27) S. R. Kumer, C. Suresh, A. K. Vasudevan, N. R. Suja, P. Mukundan and K. G. K. Warrier: Mater. Lett. 38 (1999) 161-166.

28) H. Kominami, M. Kohno, Y. Matsunaga and Y. Kera: J. Am. Ceram. Soc. 84 (2001) 1178-1180.

29) K. Okada, N. Yamamoto, Y. Kaneshima, A. Yasumori and K. J. D. Mackenzie: J. Am. Ceram. Soc. 84 (2001) 1591-1596.

30) M. Anpo, H. Nakaya, S. Kodama, Y. Kubokawa, K. Domen and T. Onishi: J. Phys. Chem. 90 (1985) 1633-1636.

31) H. Yamashita, S. Kawasaki, Y. Ichikawa, M. Harada, M. Takeuchi, G. Stewart, M. A. Fox, C. Louis, M. Che and M. Anpo: J. Phys. Chem. B 102 (1998) 5870-5875.

32) L. A. Grunes: Phys. Rev. B 27 (1983) 2111-2131.

33) Z. Y. Wu, G. Ouvard, P. Gressier and C. R. Natoli: Phys. Rev. B 55 (1997) 10382-10391.

34) L. X. Chen, T. Rajh, Z. Wang and M. C. Thurnauer: J. Phys. Chem. B 101 (1997) 10688-10697.

35) T. L. Hanley, V. Luca, I. Pickering and R. F. Howe: J. Phys. Chem. B 106 (2002) 1153-1160.

36) A. G. Mckale, B. W. Veal, A. P. Paulikas, S. K. Chan and G. S. Knapp: J. Am. Chem. Soc. 110 (1988) 3763-3768.

37) J. E. Moulder, W. F. Stickle, P. E. Sobol and K. D. Bomben: Handbook of X-ray photoelectron spectroscopy; (Physical Electronics Inc.: Eden Prairie, MN, 1995).

38) Y. L. Lin, T. J. Wang and Y. Jin: Powder Technol. 123 (2002) 194-198.

39) M. Ramirez-Del-Solar, N. De la Rosa-Fox, L. Esquivias and J. Zarzycki: J. Non-Cryst. Solids 121 (1990) 84-89.

40) H. Izumi, P. K. Nair, K. Maeda, Y. Kiyozumi and F. Mizukami: Mater. Res. Bull. 32 (1997) 1303-1311.

41) C. Anderson and A. J. Bard: J. Phys. Chem. B 101 (1997) 2611-2616.

42) S. Iwamoto, S. Iwamoto and M. Inoue: Chem. Mater. 17 (2005) 650655 . 